\title{
Panduan Lingkungan Ruang Kelas Berorientasi Multiple Intelegences di Sekolah Dasar
}

\author{
Ludfi Arya Wardana ${ }^{1}$, Uswatun Hasanah ${ }^{1}$ \\ ${ }^{1}$ Pendidikan Guru Sekolah Dasar-Universitas Panca Marga Probolinggo
}

\begin{tabular}{l}
\hline INFO ARTIKEL \\
\hline Riwayat Artikel: \\
Diterima: 17-01-2019 \\
Disetujui: 17-04-2019 \\
\hline
\end{tabular}

Kata kunci:

classroom enviroment; multiple intelegences; lingkungan ruang kelas; multiple intelegences

\author{
Alamat Korespondensi: \\ Ludfi Arya Wardana \\ Pendidikan Guru Sekolah Dasar \\ UPM Probolinggo \\ Jl. Yos Sudarso No. 107 Pabean, Dringu, Probolinggo \\ E-mail: ludfiaryawardana@upm.ac.id.
}

\begin{abstract}
The research and development was carried out in class V SDN Sukabumi 2 Probolinggo city and SDN Purutrejo 2 Pasuruan city had the aim of producing a multiintelligence oriented classroom environment guide product. The research method with Borg \& Gall as its model was modified into: (1) information gathering, (2) planning, (3) product development, (4) expert validation, (5) field trials, (6) final products. The results of the study are validation of learning technology experts score $88.3 \%$ valid criteria. Validation of linguists score $81.6 \%$ valid criteria. Field validation scores $78.5 \%$ valid criteria. Conclusion product guide for thematic classroom environment oriented multiple intelligences has a high level of validity, readability, and applicability so that this product matches the theoretical foundation and can be applied in elementary schools. Suggestions for disseminating products to improve the quality of local education.
\end{abstract}

ABSTRAK

\begin{abstract}
Abstrak: Penelitian dan pengembangan dilakukan di kelas V SDN Sukabumi 2 kota Probolinggo dan SDN Purutrejo 2 kota Pasuruan mempunyai tujuan menghasilkan produk panduan lingkungan ruang kelas berorientasi multiple intelegences. Metode penelitian dengan Borg \& Gall sebagai modelnya yang dimodifikasi menjadi: (1) pengumpulan informasi, (2) perencanaan, (3) pengembangan produk, (4) validasi ahli, (5) uji coba lapangan, (6) produk akhir. Hasil penelitian yaitu validasi ahli teknologi pembelajaran skor $88,3 \%$ kriteria valid. Validasi ahli bahasa skor $81,6 \%$ kriteria valid. Validasi lapangan skor 78,5\% kriteria valid. Kesimpulan produk panduan lingkungan ruang kelas berorientasi multiple intelegences mempunyai tingkat validitas, keterbacaan dan keterterapan tinggi sehingga produk ini sesuai landasan teoritik dan dapat diterapkan di sekolah dasar. Saran dilakukan penyebarluasan produk untuk meningkatkan kualitias pendidikan setempat.
\end{abstract}

Lingkungan sekolah merupakan miniatur belajar bagi siswa, disitulah sebagian besar waktu siswa di sekolah akan dihabiskan untuk belajar, bermain, dan mengembangkan potensinya. Selain itu, stimulasi lingkungan juga memiliki pengaruh yang cukup besar. Saat belajar di dalam kelas, saat itu pula siswa akan berinteraksi dengan segala sesuatu yang berada di didalamnya. Siswa akan mengalami perubahan perilaku kognitif, afektif, dan psikomotor (Syah, 2011) sebagai akibat dari interaksi dengan lingkungannya (Hanafiah \& Suhana, 2010). Lingkungan ini dapat berupa lingkungan belajar, yaitu segala material yang ada di luar dan dalam kelas yang dapat mendukung proses belajar siswa. Hal ini juga didukung Cryer et al. (2005) yaitu lingkungan belajar siswa dapat meningkatkan hubungan anak sehingga meningkatkan kemampuan belajar.

Solusi pengembangan dalam penerapan panduan lingkungan ruang kelas adalah dengan memasukkan muatan Multiple Intelligences di dalam kegiatan pembelajaran. Gardner (2003) menjelaskan bahwa terdapat delapan kecedasan dalam teori MI, yaitu (1) kecerdasan linguistik, (2) logis-matematis, (3) visual spasial, (4) musikal, (5) kinestetik, (6) interpersonal, (7) intrapersonal, dan (8) naturalistik. Kecerdasan-kecerdasan tersbut dapat mengoptimalkan kinerja otak dengan baik. Hal ini dibuktikan dengan adanya hasil penelitian yang dilakukan oleh Ghraibel (2012) tentang "Design and Its Relation with Multiple Intelligences" bahwa kecerdasan interpersonal, kecerdasan logis-matematis, kecerdasan kinestetik, dan kecerdasan linguistik berhubungan dengan otak kiri, sedangkan kecerdasan musikal dan kecerdasan spasial dengan belahan kanan. Selain itu, Coban \& Dubaz (2011) mengemukakan bahwa desain lingkungan belajar dengan bernuansa kecerdasan majemuk siswa dapat memengaruhi keaktifan pembelajaran. Pendapat lain oleh Aydemir \& Karalı (2014) mengatakan bahwa area kelas multiple intelegences mempunyai nilai-nilai yang dapat menstimulus otak sehingga berpengaruh dalam kecerdasan otak. 
Studi pendahuluan berupa observasi di SDN Sukabumi 2 kota Probolinggo dan SDN Purutrejo 2 Kota Pasuruan dapat diperoleh informasi bahwa (1) pembelajaran dilakukan hanya beracuan pada buku guru, (2) kesulitan untuk mengembangkan kegiatan pembelajaran, (3) belum dapat menerapkan lingkungan kelas atau pendekatan lain dalam pembelajaran, (4) kesulitan untuk memilih jenis desain kelas yang dapat menunjang pembelajaran tematik, dan (5) kesulitan untuk mengkolaborasikan pembelajaran tematik dengan inovasi lain. Dampaknya pada kegiatan pembelajaran bahwa (1) siswa kurang termotivasi dalam pembelajaran di kelas, (2) hanya 6-8 saja dari 39 siswa yang aktif bertanya jawab dengan guru, (3) siswa kurang terfokus saat guru memberikan penjelasan, (4) siswa kurang betah berada di dalam kelas sehingga ingin segera istirahat, (5) pembelajaran belum mencerminkan pembelajaran yang dapat mengkonstruksi kecerdasan majemuk, dan (6) pembelajaran kurang menarik perhatian siswa. Berdasarkan pemaparan di atas, dapat diupayakan beberapa alternatif sebagai solusi dari permasalahanpermasalahan yang muncul, yaitu (1) mengembangkan lingkungan ruang kelas yang dapat mengaktifkan siswa, (2) mengembangkan atau menggunakan kecerdasan majemuk, dan (3) mengembangkan atau menggunakan jenis ruang kelas kelas secara bervariasi agar siswa tidak jenuh di kelas.

Paparan di atas peneliti berpendapat bahwa solusi permasalahan tersebut dapat dilakukan melalui perbaikan lingkungan ruang kelas. Menurut Wang (2017) lingkungan ruang kelas dapat memicu keterlibatan perilaku, emosional dan kognitif siswa. Selain itu, Serin, dkk (2009) gaya mengajar dengan desain multiple intelegences berpengaruh signifikan terhadap spasial /visual, naturalistik, dan kecerdasan interpersonal memainkan peran prediktif pada strategi pengajaran. Pendapat sama dikemukakan oleh Akkuzu \& Akçay (2011) bahwa kecerdasan majemuk yang diterapkan dapat meningkatkan motivasi intrinsik siswa. Artinya, desain kelas tematik berorientasi multiple intelgences merupakan solusi tepat untuk mengatasi permasalahan tersebut.

Penelitian terdahulu yang dilakukan Byl \& Kloet (2014) dengan judul The Effect of The Physical Classroom Environment on Literacy Outcome, mempunyai dua variabel, yaitu lingkungan kelas dan literasi. Metode penelitian analisis kualitatif. Hasil penelitian yaitu konsep pembelajaran konstruktifistik membantu pembelajaran yang efektif. Selain itu, desain lingkungan kelas yang nyaman dapat membantu siswa untuk belajar. Hubungan variabel sekarang adalah terdapat variabel penelitian lingkungan fisik kelas sehingga penelitian ini relevan. Penelitian Kılıç \& Sert (2015) dengan judul Primary school 5th grade science and technology lesson book's investigation of multiple intelligence theory, penelitian tersebut memiliki variabel, yaitu kecerdasan majemuk. Metode analisis data menggunakan analisis kualitatif. Penelitian ini menghasilkan teori kecerdasan majemuk cocok untuk verbal, logis dan kecerdasan visual dan tidak cukup sesuai dengan kecerdasan interpersonal, intrapersonal, kinestetik tubuh, dan naturalistik. Hubungan dengan variabel sekarang adalah terdapat variabel multiple intelegences.

Penelitian Sorin-Avram (2014) dengan judul From theory to practice: the multiple intelligences theory experience in a Romanian secondary school, penelitian tersebut memiliki variabel, yaitu teori dan praktek multiple intelegences. Metode analisis data menggunakan analisis kuantitatif. Berdasarkan hasil analisis didapatkan teori dan praktek kecerdasan majemuk meningkatkan kecerdasan matematika logis dan linguistik dengan disesuaikan dengan kurikulum yang ada. Hubungan dengan variabel sekarang adalah kecerdasan majemuk. Berdasarkan pada seluruh penjelasan di atas maka peneliti akan melakukan penelitian pengembangan yang berjudul "Panduan Lingkungan ruang Kelas Tematik berorientasi Multiple Intelligences di Sekolah Dasar." Penelitian ini merupakan langkah konkret sebagai alternatif solusi dalam menyelesaikan permasalahan yang terjadi.

\section{METODE}

Metode penelitian yang digunakan dalam mengembangan produk panduan lingkungan ruang kelas berorientasi multiple intelligences menggunakan model pengembangan model Borg \& Gall (1983). Penelitian ini menggunakan model Borg \& Gall yang telah dimodifikasi menjadi (1) pengumpulan informasi, (2) perencanaan, (3) pengembangan produk, (4) validasi ahli, (5) uji coba lapangan, (6) produk akhir. Selain itu, model ini memiliki tahapan-tahapan yang sangat jelas dan terperinci sehingga pengembangan dapat dilakukan dengan baik, sebagaimana tersaji pada gambar 1.

Langkah awal dalam penelitian ini adalah melakukan studi pendahuluan. Kegiatan-kegiatan yang dilakukan, yaitu (a) studi literatur, (b) survei lapangan, (c) identifikasi kebutuhan, dan (d) identifikasi masalah. Kegiatan-kegiatan ini dilakukan untuk pengumpulan informasi awal sebagai modal awal melaksanakan penelitian. Setelah studi pendahuluan, dilanjutkan penyusunan rencana pelaksanaan penelitian.

Kegiatan yang dilakukan dalam perencanaan adalah mengkaji data yang diperoleh dari studi pendahuluan, melakukan analisis pengembangan lingkungan ruang kelas berorientasi multiple intelegences yang akan menjadi solusi dari permasalahan, menentukan kelas yang akan menjadi tempat desain, jadwal penelitian, perencanaan validasi pengembangan produk dengan menyusun instrumen penilaian, serta uji coba di lapangan. Kegiatan perencanaan ini dilakukan agar penelitian menjadi sistematis dan prosedural. 
Pada tahap pengembangan produk, peneliti mulai menyusun produk yang akan diteliti dan dikembangkan meliputi semua aspek lingkungan ruang kelas seperti menyusun panduan lingkungan ruang kelas tematik berorientasi multiple intelegences bagi guru yang berisi bahasan (1) konsep ruang kelas, (2) komponen ruang kelas, (3) prinsip-prinsip ruang kelas, (4) karakteristik siswa sekolah dasar, (5) lingkungan ruang kelas di sekolah dasar, serta menyusun ruang kelas yang meliputi (1) panduan analisis kebutuhan kelas, (2) analisis kelebihan kelas, (3) analisis kekurangan kelas, (4) langkah-langkah mendesain kelas.

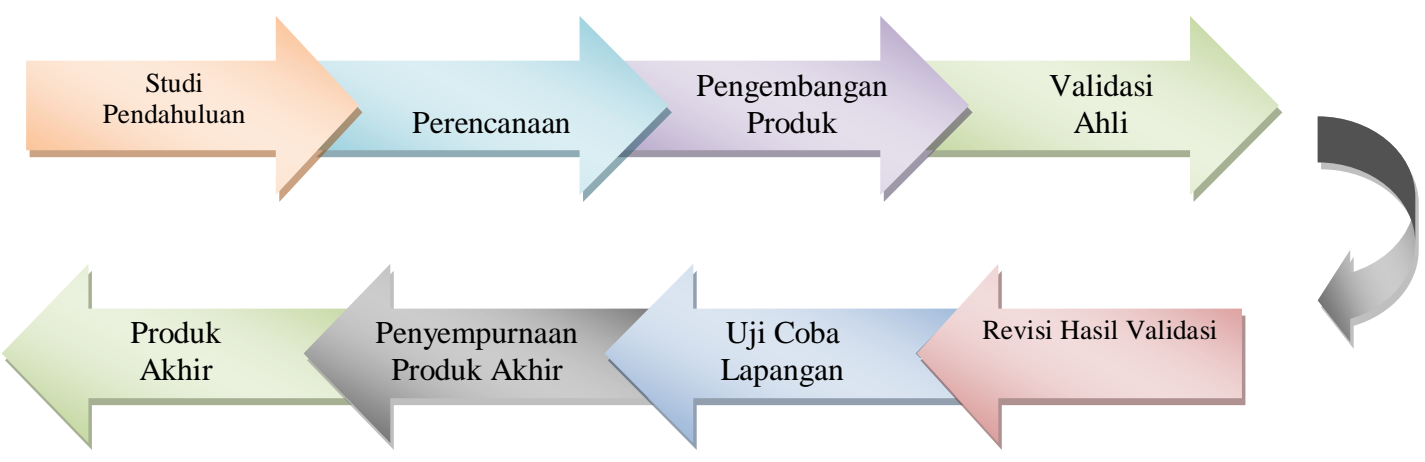

Gambar 1. Diagram Alir Penelitian dan Pengembangan Lingkungan Ruang Kelas Berorientasi Multiple Intelligence (Sumber: Olahan Peneliti, Adaptasi Borg \& Gall, 1983:775)

Uji coba kelayakan produk yang dilakukan, meliputi (1) uji validasi dari ahli teknologi pembelajaran (TEP), ahli bahasa dan kepraktisan dan (2) uji coba lapangan. Validasi ahli dilakukan dengan menggunakan instrumen validasi yang telah disusun. Hal ini dilakukan untuk mengetahui kesesuaian produk yang telah disusun dan dikembangkan secara teoritik. Subjek uji coba meliputi ahli TEP, ahli bahasa dan kepraktisan, guru kelas V SDN Sukabumi 2 kota Probolinggo dan SDN Purutrejo 2 Kota Pasuruan. Instrumen pengumpulan data yang digunakan antara lain lembar validasi para ahli dan angket tanggapan guru. Tahap pengeyempuraan produk, peneliti melakukan revisi untuk perbaikan produk yang dikembangkan berdasarkan ujicoba skala terbatas. Dengan menyelesaikan perbaikan produk, maka selanjutnya diperoleh produk akhir berupa panduan penggunaan lingkungan ruang kelas berbasis tematik berorientasi multiple intelegences di sekolah dasar.

Analisis data yang digunakan dalam penelitian dan pengembangan ini yaitu analisis deskriptif kualitatif dan deskriptif kuantitatif. Analisis data kualitatif digunakan untuk mengolah data dari ahli dan pengguna. Sedangkan analisis data kuantitatif dilakukan pada skor angket dan tes. Analisis data ini dimaksudkan untuk mengetahui tingkat ketercapaian berdasarkan kriteria yang telah ditentukan. Instrumen pengumpul data pada penelitian ini terbagi menjadi dua, pertama instrumen pengumpulan data pada pengumpulan informasi pendahuluan dan pengumpul data pada penelitian pengembangan. Insrumen pengumpul data pada penelitian disajikan pada tabel 1 .

Tabel 1. Rincian Pedoman Menyusun Instrumen dan Fungsinya

\begin{tabular}{|c|c|c|c|c|}
\hline No & Data & Komponen Data & Instrumen & Responden \\
\hline \multirow[t]{12}{*}{1} & Validitas Desain & Validasi Isi & Angket & Ahli TEP \\
\hline & & 1.1 Keselarasan lingkungan kelas berorientasi MI & & \\
\hline & & 1.2 Keselarasan teori ruang kelas dan MI & & \\
\hline & & 1.3 Keakuratan sarpras fisik kelas & & \\
\hline & & Validasi Penyajian & Angket & Ahli TEP \\
\hline & & 1.4 Keutuhan ruang kelas berorientasi MI & & \\
\hline & & 1.5 Keutuhan cara dan petunjuk & & \\
\hline & & 1.6 Keutuhan gambaran desain & & \\
\hline & & Validasi Grafika & Angket & Ahli TEP \\
\hline & & 1.7 Keakuratan ukuran, skala, dan tata letak & & \\
\hline & & 1.8 Keakuratan pemilihan warna dan karakter & & \\
\hline & & 1.9 Kejelasan cetakan gambaran desain & & \\
\hline \multirow[t]{4}{*}{2} & Validitas Buku & Validasi Isi & Angket & Ahli TEP \\
\hline & Panduan & 2.1 Keselarasan konsep dan teori & & \\
\hline & & 2.2 Kekuratan prosedur pengaturan & & \\
\hline & & 2.3 Ketepatan dan kesahihan materi & & \\
\hline
\end{tabular}


Tabel 1. Rincian Pedoman Menyusun Instrumen dan Fungsinya (Lanjutan)

\begin{tabular}{lll}
\hline Validasi Penyajian & Angket & Ahli TEP \\
2.4 Kesesuaian contoh dan desain & & \\
2.5 Konsistensi sistematika & \\
2.6 Keruntutan isi panduan & \\
$\mathbf{2 . 7}$ Kelogisan alur desain isi buku & & \\
Validasi Grafika & Angket & Ahli TEP \\
2.8 Keakuratan font; jenis dan ukuran huruf & & \\
2.9 Keakuratan desain dan ukuran layout & & \\
2.10 Kesesuaian tampilan, ilustrasi, & & \\
2.11 Ketepatan kertas, pencetakan, jilid & & \\
\hline
\end{tabular}

Tabel 2. Kisi-kisi Instrumen Uji Coba Buku Panduan (Praktisi)

\begin{tabular}{|c|c|c|c|c|}
\hline No & Data & Komponen Data & Instrumen & Responden \\
\hline \multirow[t]{18}{*}{1} & Validitas Buku & Validasi Kaidah Kebahasaan & - $\quad$ Angket & Praktisi (Guru) \\
\hline & Panduan & 1.1 Keselarasan tata bahasa & - $\quad$ Pedoman Wawancara & \\
\hline & & 1.2 Keakuratan kata EYD & & \\
\hline & & 1.3 Efisien struktur kalimat & & \\
\hline & & 1.4 Keakuratan huruf dan tanda baca & & \\
\hline & & Validasi Penyajian & - $\quad$ Angket & Praktisi (Guru) \\
\hline & & 1.5 Sistematis penyajian buku & - $\quad$ Pedoman Wawancara & \\
\hline & & 1.6 Keakuratan penggunaan istilah & & \\
\hline & & 1.7 Keakuratan tata letak dan tipografi teks & & \\
\hline & & 1.8 Keakuratan dan kemutakhiran & & \\
\hline & & Validasi Alur Materi & - $\quad$ Angket & Praktisi (Guru) \\
\hline & & 1.9 Kesesuaiaan penggunaan bahasa & - $\quad$ Pedoman Wawancara & \\
\hline & & 1.10 Ketepatan penyajian materi & & \\
\hline & & 1.11 Ketepatan dan interaktif & & \\
\hline & & Validasi Keterbacaan & - $\quad$ Angket & Praktisi (Guru) \\
\hline & & 1.12 Keefektifan membaca tulisan & - $\quad$ Pedoman Wawancara & \\
\hline & & 1.13 Keefektifan pemahaman petunjuk & & \\
\hline & & 1.14 Ketepatan dan kesesuaian isi & & \\
\hline
\end{tabular}

Metode analisis data menggunakan analisis data kualitatif dan kuantitatif. Analisis data kualitatif digunakan untuk mengolah data dari ahli dan pengguna. Analisis data kuantitatif dilakukan pada skor angket. Analisis data ini dimaksudkan untuk mengetahui tingkat ketercapaian berdasarkan ukuran yang ditentukan. Kriteria dalam pedoman interpretasi disajikan pada tabel 3.

$$
\mathrm{Vm} \quad \mathrm{Va}=\frac{T S e}{T S h} \times 100 \% \quad \mathrm{Vp}=\frac{T S e}{T S h} \times 100 \% \quad \mathrm{Ve}=\frac{T S e}{T S h} \times 100 \%
$$

$\mathrm{Vm}=$ Validitas Ahli, $\mathrm{Vp}=$ Validitas Pengguna, $\mathrm{Ve}=$ Validitas Audience, $\mathrm{TSh}=$ Total Skor Maksimal yang diharapkan. Tse $=$ Total Skor Empiris (Hasil Validasi dari validator) $100 \%=$ Konstanta

Tabel 3. Tabel Kriteria Kevalidan Desain Ruang Kelas Berbasis Tematik

\begin{tabular}{lll}
\hline No. & Kriteria Validitas & \multicolumn{1}{c}{ Tingkat Efektivitas } \\
\hline 1. & $86-100 \%$ & Sangat Baik (dapat digunakan tanpa revisi) \\
\hline 2. & $70-85 \%$ & Cukup Baik (dapat dipergunakan dengan revisi) \\
\hline 3. & $60-69 \%$ & Tidak Baik (tidak dapat dipergunakan) \\
\hline 4. & $0-59 \%$ & Sangat Tidak Baik \\
\hline
\end{tabular}

Sumber diadaptasi dari (Rulyansah \& Wardana, 2018) 


\section{HASIL}

Validasi ahli teknologi pembelajaran dilakukan oleh Bapak Afib Rulyansah, S.Pd., M.Pd. Beliau merupakan salah satu ahli teknologi pembelajaran dan penelitiannya banyak tentang pendidikan dasar serta multiple intelegences. Hasil yang didapatkan berupa hasil kuantitatif berupa skor dan kualitatif berupa saran dan komentar. Hasil skor produk menunjukan sebesar 88,3\% dan hasil tersebut mendapat kriteria valid. Adapun hasilnya pada tabel 4.

Tabel 4. Hasil Validasi Ahli Teknologi Pembelajaran

\begin{tabular}{llc}
\hline No. & Kriteria & Skor \\
\hline 1.1 & Keselarasan lingkungan kelas berorientasi MI & \\
\hline 1. & Buku panduan memuat konsep ruang kelas berorientasi MI di sekolah dasar. & 4 \\
\hline 2. & Buku panduan memuat teori ruang kelas beorientasi MI yang spesifik dan sahih. & 3 \\
\hline 3. & Buku panduan menyajikan tentang prinsip dan bentuk-bentuk ruang kelas yang memadai. & 4 \\
\hline 1.2 & Keselarasan teori desain dan MI & \\
\hline 4. & Buku panduan menyajikan desain pengaturan dan penataan lingkungan ruang kelas dan MI & 3 \\
\hline 5. & Buku panduan disertai konsep dan teori gambaran ruang berbasis dan MI & 3 \\
\hline 6. & Buku panduan mencangkup prosedur penerapan lingkungan ruang kelas dan MI & 3 \\
\hline 1.3 & Keakuratan sarana dan prasarana fisik kelas & \\
\hline 7. & Desain dan penerapan sesuai dengan sarana di kelas & 3 \\
\hline 8. & Desain sesuai karater siswa & 3 \\
\hline 9. & Desainruang kelas sesuai kebutuhan siswa & 4 \\
\hline Jumlah & 30 \\
\hline Total Persentase & $83,3 \%$ \\
\hline
\end{tabular}

Berdasarkan hasil skor validasi TEP, maka produk mendapatkan saran dan komentar. Saran dan komentar perbaikan yaitu, prinsip-prinsip lingkungan kelas berorientasi MI dapat diberikan bagan atau gambar hubungan antara visibilitas, aksesibilitas, fleksibilitas, kenyamanan, keindahan dan visibilitas. Berikut pada fotol hasil perbaikan sebelum dan sesudah dari saran validator. Validasi ahli bahasa dilakukan oleh Ibu Rofika Nuriyanti, S.Pd., M.Pd. Beliau merupakan salah satu ahli bahasa dan penelitiannya banyak tentang kebahasaan. Hasil yang didapatkan berupa hasil kuantitatif berupa skor dan kualitatif berupa saran dan komentar. Hasil skor produk menunjukan sebesar 81,6\% dan hasil tersebut mendapat kriteria valid. Adapun hasilnya pada tabel 5. Berdasarkan hasil skor validasi bahasa, maka produk mendapatkan saran dan komentar. Saran dan komentar perbaikan yaitu, pada setiap BAB mohon dikasih petunjuk pengantar awal (rasionalisasi) sebelum masuk ke inti pembahasan. Gambar 2 menunjukkan ketika uji coba dengan ahli bahasa di ruang kelas bersama siswa dan guru.

Validasi lapangan dilakukan oleh guru kelas V SDN Sukabumi 2 kota Probolinggo dan SDN Purutrejo 2 Kota Pasuruan. Beliau merupakan salah satu guru yang sudah berpengalaman 10 tahun mengajar di SDN Sukabumi 2 Kota Probolinggo. Hasil yang didapatkan berupa hasil kuantitatif berupa skor dan kualitatif berupa saran dan komentar. Hasil skor produk menunjukan sebesar 78,5\% dan hasil tersebut mendapat kriteria valid. Adapun hasilnya pada tabel 6.

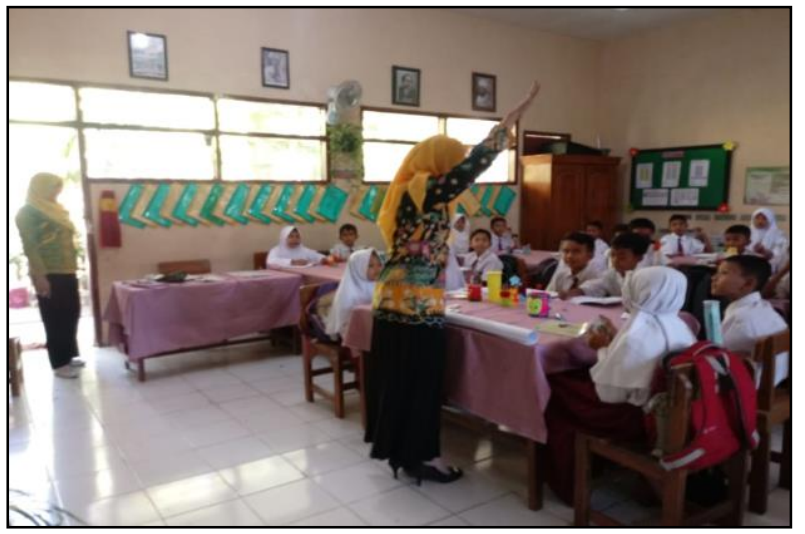

Gambar 1. Revisi Keadaan Ruang Kelas Berorientasi MI 


\section{Tabel 5. Hasil Validasi Ahli Bahasa}

\begin{tabular}{clc}
\hline No & Kriteria & Skor \\
\hline $\mathbf{2 . 1}$ & Kelugasan petunjuk dalam buku panduan & \\
\hline 1. & Petunjuk bahasa yang mudah dipahami. & 3 \\
\hline 2. & Petunjuk disusun dalam kalimat yang jelas dan padat. & 4 \\
\hline 3. & Petunjuk disertakan dengan prosedur penggunaan buku & 3 \\
\hline $\mathbf{2 . 2}$ & Kemudahan pemahaman alur materi & 4 \\
\hline 4. & Buku panduan disajikan dalam bahasa yang komunikatif. & 3 \\
\hline 5. & Buku panduan disajikan secara runtut dan sistematis. & \\
\hline $\mathbf{2 . 3}$ Ketepatan EYD & 3 \\
\hline 6. & Buku panduan sesuai dengan EYD. & 3 \\
\hline 7. & Bahasa yang digunakan formal dan santun. & 3 \\
\hline 8. & Istilah bahasa yang digunakan konsisten & 26 \\
\hline & Jumlah & $81,6 \%$ \\
\hline
\end{tabular}

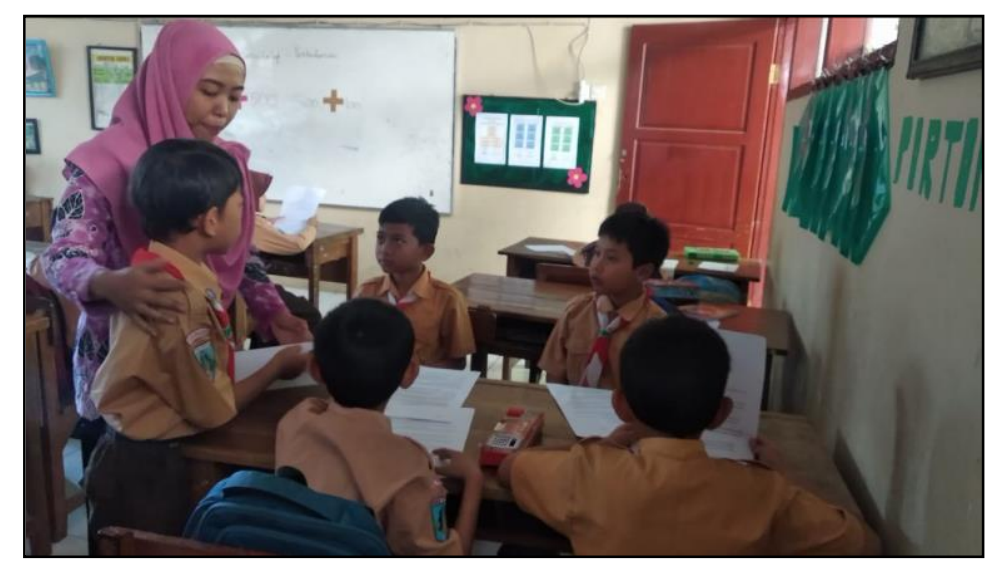

Gambar 2. Proses Validasi Ahli Bahasa

Tabel 6. Hasil Validasi Lapangan

\begin{tabular}{clc}
\hline No & \multicolumn{1}{c}{ Kriteria } & Skor \\
\hline 1.1 & Kemudahan penggunaan buku panduan & \\
\hline 1. & Buku panduan mudah digunakan oleh guru & 4 \\
\hline 2. & Buku panduan mudah & 4 \\
\hline 1.2 & Kelengkapan isi buku panduan & 3 \\
\hline 1. & Buku panduan disertai dengan mekanisme desain ruang kelas yang runtut & 4 \\
\hline 2. & Buku panduan disertai contoh ilustrasi desain & 3 \\
\hline 3. & Setiap langkah dan ilustrasi yang disajikan lengkap dan jelas. & 3 \\
\hline 1.3 & Kemudahan penerapan desain ruang kelas & 3 \\
\hline 1. & Prosedur desain ruang kelas mudah diterapkan & 22 \\
\hline 2. & Penerapan didesaian dengan waktu, biaya, pengadaan sarana dan prasana secara efisien & $78,5 \%$ \\
\hline Jumlah
\end{tabular}

Berdasarkan hasil skor validasi lapangan dari guru kelas V di SDN Sukabumi 2 kota Probolinggo, maka produk mendapatkan saran dan komentar. Saran dan komentar perbaikan yaitu pada halaman 58 tentang letak formasi meja kursi belum dikuatkan dengan ilustrasi, mohon dilengkapi agar jelas. Gambar 3 merupakan proses validasi lapangan. 


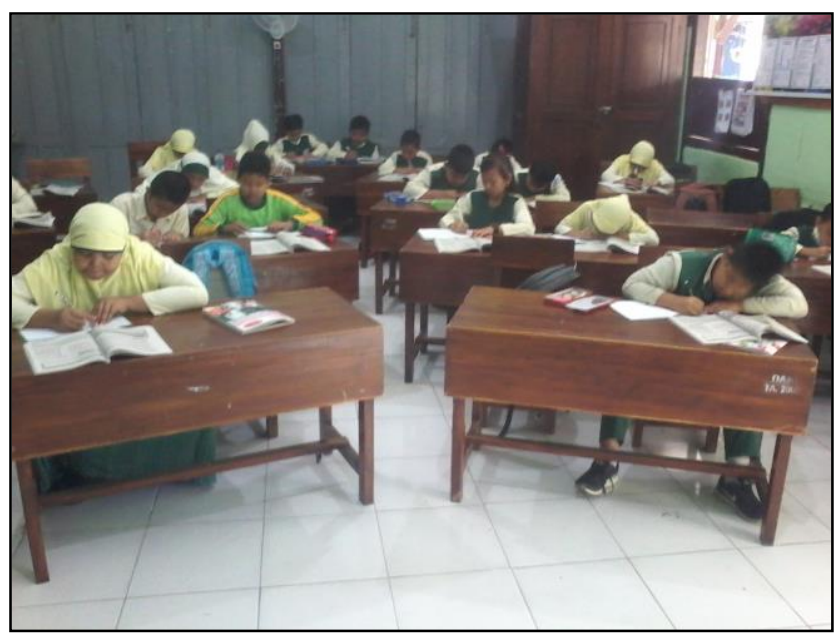

\section{Gambar 3. Proses Validasi Lapangan di SDN Sukabumi 2 Kota Probolinggo}

\section{PEMBAHASAN}

Penyusunan panduan lingkungan ruang kelas berorientasi multiple intelegences terdiri atas perencanaan yang matang, pengadaan sarana dan prasarana secara kontinyu dan selalu mengikutsertakan warga sekolah. Mulyono (2008) menegaskan bahwa pengelolaan sarana belajar siswa harus direncakan dan pengadaannya harus dilakukan secara berkelanjutan untuk mendukung proses pembelajaran. Pandangan senada juga disampaikan Maisyaroh., Burhanuddin., \& Imron (2004) bahwa tata kelola sarana dan prasarana belajar selalu terkait dengan sumber daya manusia (guru dan warga sekolah lainnya).

Prinsip penyusunan panduan ruang kelas berorientasi multiple intelegences melibatkan dimensi visibilitas, aksesibilitas, fleksibilitas, kenyamanan, dan keindahan. Telaah berbagai bidang perlu dilakukan untuk menjamin iklim belajar yang positif. Manajemen materi-materi di sekitar siswa seperti perkakas kelas, suhu, kombinasi warna, aspek fonetik, gerakan, sirkulasi udara, aroma, dan pencahayaan perlu dilakukan. Selain itu, untuk mecapai perkembangan diri siswa yang optimal, warga sekolah seharusnya menyediakan kebutuhan para pebelajar (Sumantri, 2015).

Penyusunan panduan lingkungan ruang kelas tematik berorientasi multiple intelegences diharapkan dapat membantu guru untuk membangun iklim pembelajaran yang menyenangkan. Lingkungan belajar siswa yang kondusif mampu menghadirkan pembelajaran bermakna sehingga ilmu yang didapatkan pebelajar dapat bertahan lebih lama (Anderson \& Krathwohl, 2010). komunikasi di dalam kelas terbentuk untuk memengaruhi pembelajaran. Komunikasi ini dapat berupa perkakas yang digunakan dalam menciptakan pola hubungan pembelajaran seperti poster, papan buletin, buku, bahan bacaan lainnya, video, dan komunikasi lisan yang dilakukan oleh pengajar (Lachica, 2015). Komponen fisik di dalam kelas dapat memberikan kontribusi positif terhadap proses pembelajaran.

Hasil revisi dari ahli validasi teknologi pembelajaran merupakan langkah untuk memperoleh produk yang lebih sempurna. Berdasarkan hasil validasi teknologi pembelajaran memperoleh $83,3 \%$ dengan kriteria valid. Saran dari ahli berupa perbaikan prinsip-prinsip lingkungan ruang kelas berorientasi multiple intelegences dapat diberikan bagan atau gambar hubungan antara visibilitas, aksesibilitas, fleksibilitas, kenyamanan, keindahan dan visibilitas. Hal ini oleh peneliti diperbaiki sesuai dengan catatan yang diberikan oleh ahli. Hal ini sesuai dengan Sorin-Avram (2014) mengemukakan bahwa prinsipprinsip lingkungan ruang kelas yaitu visibilitas, aksesibilitas, fleksibilitas, kenyamanan, keindahan sehingga masing-masing prinsip ini harus saling berkaitan. Artinya, dengan prinsip tersebut bertujuan untuk meningkatkan kenyamanan siswa. Pendapat yang sama oleh Voss, Wagner, Khusmann, Trautwein, \& Kunter (2017) yang mengungkapkan bahwa desain kelas dirubah secara berkala karena memengaruhi emosional guru dalam meningkatkan motivasi.

Validasi dari ahli bahasa terkait tingkat kebahasaan produk panduan lingkungan ruang kelas berorientasi multiple intelegences mendapatkan skor $81,6 \%$ kriteria valid. Saran dari ahli yaitu pada setiap BAB mohon dikasih petunjuk pengantar awal sebelum masuk ke inti pembahasan. Hal ini oleh peneliti ditindaklanjuti agar memperoleh produk yang lebih sempurna. Hal ini sesuai dengan Piengkes, dkk (2014) yang mengemukakan bahwa dalam penjelasan tentang komponen lingkungan ruang kelas harus disertai analisis kebutuhan siswa dan rasionalisasi karakteristik siswa. Pendapat sama Leblanc (2017) mengemukakan bahwa lingkungan ruang kelas harus mempunyai rasionalisasi dalam menentukan komponen-komponen kelas.

Berdasarkan hasil validator TEP dan bahasa yang telah ditindaklanjuti perbaikan, maka langkah selanjutnya validasi lapangan untuk memperoleh hasil produk yang maksimal. Validasi lapangan dilakukan oleh guru kelas V SDN Sukabumi 2 kota Probolinggo. Hasil validasi lapangan dengan skor 78,5\% dengan kriteria valid. Saran dan komentar validator lapangan telah ditindaklanjuti berupa halaman 58 tentang letak formasi meja kursi belum dikuatkan dengan ilustrasi, mohon dilengkapi 
biar jelas. Hal ini sesuai dengan Yeganeh \& Dezfouli (2015) yang mengemukakan bahwa pada lingkungan ruang kelas harus terdapat jenis formasi-formasi kelas yang bervariasi sehingga dapat meningkatkan motivasi siswa. Artinya, formasi ini dapat bernuansa sesuai dengan kebutuhan misalnya, multiple integences sehingga dapat meningkatkan kecerdasan siswa.

Hasill riset pengembangan ini berkualifikasi sangat layak untuk diimplementasikan di sekolah dasar. Temuan riset ini menunjukkan bahwa hasil penelitian memperlihatkan adanya kekuatan dan kelemahan. Kekuatan dari produk adalah (1) formasi kelas lebih berbobot dengan disesuaikan karakteristik sehingga siswa merasa tertantang dalam pembelajaran karena berhubungan dengan kehidupan mereka; (2) pengaturan kelas sangat diminati siswa, hal ini terlihat dari hasil implementasi pengaturan kelas berorientasi multiple intelegences dengan kualifikasi sangat layak; (3) peserta didik aktif saat proses pembelajaran dengan memanfaatkan perkakas kelas sebagai sumber belajar; (4) kenyamanan siswa dalam belajar sangat terlihat saat mereka dapat memandang perkakas kelas; (5) buku panduan pengaturan kelas berorientasi multiple intelegences dapat membantu guru dalam melakukan pengaturan kelas. Kelemahan produk juga terlihat selama penelitian, yaitu (1) fleksibilitas penerapan pengaturan kelas perlu ditingkatkan karena tidak semua kelas dapat mengimplementasikan pengaturan kelas ini, karena dipengaruhi pada variabel sarana prasarana yang dimiliki sekolah, (2) persiapan yang berkelanjutan perlu dilakukan karena karakteristik siswa yang naik kelas bisa dimungkinkan sangat berbeda, (3) pengaturan kelas membutuhkan persiapan dan anggaran dana yang lebih.

\section{SIMPULAN}

Berdasarkan hasil uji validasi ahli dan lapangan produk panduan lingkungan ruang kelas berorientasi multiple intelegences, maka dapat disimpulkan bahwa ditinjau dari validasi ahli teknologi pembelajaran 83,3\% kriteria valid sehingga produk ini sesuai dengan landasan teoritik maupun penelitian terdahulu. Ditinjau dari validasi ahli bahasa produk panduan ruang kelas berorientasi multiple intelegences $81,6 \%$ kriteria valid sehingga dapat disimpulkan produk ini tingkat keterbacaannya tinggi dan mudah dipahami. Ditinjau dari uji coba lapangan di kelas V SDN Sukabumi 2 kota Probolinggo dan SDN Purutrejo 2 kota Pasuruan produk panduan lingkungan ruang kelas berorientasi multiple intelegences 78,5\% kriteria valid sehingga produk ini dapat digunakan di SD dengan menyesuaikan kebutuhan yang ada.

Hasil simpulan di atas mempunyai saran dan masukan ketika proses penelitian. Beberapa saran pemanfaatan yang didapat ketika proses penelitan yaitu, bagi guru harus memahami buku panduan terlebih dahulu sehingga dapat memetakan kebutuhan dan karakterisitik yang ada di kelasnya. Bagi peneliti selanjutnya bahwa produk ruang kelas berorientasi multiple intelegences dapat dikembangkan lagi ke variabel-variabel yang mendukung kecerdasan majemuk. Bagi pemangku kepentingan (dinas pendidikan) dapat melakukan penyebarluasan produk untuk meningkatkan kualitas pendidikan setempat.

\section{DAFTAR RUJUKAN}

Akkuzu, N., \& Akçay, H. (2011). The Design of a Learning Environment Based on the Theory of Multiple Intelligence and the Study its Effectiveness on the Achievements, Attitudes and Retention of Students. Procedia Computer Science, 3, 10031008. https://doi.org/10.1016/j.procs.2010.12.165

Anderson, L. W., \& Krathwohl, D. R. (2010). Kerangka Landasan untuk Pembelajaran, Pengajaran, dan Asesmen (Revisi Taksonomi Pendidikan Bloom). Yogyakarta: Pustaka Pelajar.

Aydemir, H., \& Karal1, Y. (2014). Study of Secondary School Students' Multiple Intelligence Areas (Malatya Case). Procedia Social and Behavioral Sciences, 152, 167-172. https://doi.org/10.1016/j.sbspro.2014.09.175

Borg, W. R., \& Gall, M. (1983). Education Reseacrh An Introduction (Fourth Edition). New York: Longman Inc.

Byl, J., \& Kloet, B. V. (2014). The Effect of The Physical Classroom Environment on Literacy Outcome. America: United States of America.

Coban, S., \& Dubaz, I. (2011). The Relationship Between Active Learning Models in Music Lessons in Elementary Schools and Multiple Intelligence Areas. Procedia - Social and Behavioral Sciences, 28, 684-690. https://doi.org/10.1016/j.sbspro.2011.11.129

Cryer, D., Wagner-moore, L., Burchinal, M., Yazejian, N., Hurwitz, S., \& Wolery, M. (2005). Effects of Transitions to New Child Care Classes on Infant / Toddler Distress and Behavior. Early Childhood Research Quarterly, 20(1), 37-56. https://doi.org/10.1016/j.ecresq.2005.01.005

Gardner, H. (2003). Kecerdasan Majemuk (Multiple Intelligences) Teori dalam Praktik. Batam: Interaksara.

Ghraibel, A. M. A. (2012). Brain Based Learning and Its Relation with Multiple Intelligences. International Journal of Psychological Studies, 4(1).

Hanafiah, N., \& Suhana, C. (2010). Konsep Strategi Pembelajaran. Bandung: PT Refika Aditama.

K1lıç, M. S., \& Sert, H. (2015). Primary School 5th Grade Science and Technology Lesson Book's Investigation of Multiple Intelligence Theory. Procedia - Social and Behavioral Sciences, 174, 2577-2581.

https://doi.org/10.1016/j.sbspro.2015.01.935 
Lachica, L. P. F. (2015). Classroom Communication and Integration: Public High School Teachers' Notions. International Journal on Integrating Technology in Education (IJITE), 4(2), 1-11. https://doi.org/10.5121/ijite.2015.4201

Leblanc, R. J. (2017). Interactional Order, Moral Order : Classroom Interactions and the Institutional Production of Identities. Linguistics and Education, 40, 27-37. https://doi.org/10.1016/j.linged.2017.05.004

Maisyaroh., Burhanuddin., \& Imron, A. (2004). Perspektif Manajemen Pendidikan Berbasis Sekolah. Malang: Universitas Negeri Malang.

Mulyono. (2008). Manajemen Administrasi \& Organisasi Pendidikan.Yogyakarta: Ar-Ruzz Media.

Piengkes, N., Wolther, S. R., Nooyod, A., \& Prameteerawatchai, P. (2014). The Study of English Achievement for the 4 th Grade Students by the Intergrated Multiple Intelligence Model. Procedia - Social and Behavioral Sciences, 116, 24782480. https://doi.org/10.1016/j.sbspro.2014.01.595

Rulyansah, A., \& Wardana, A. L. (2018). Pengembangan Media Pembelajaran Pop Up dengan menggunakan Model STAD Dalam Meningkatkan Hasil Belajar Siswa. Pedagogy, 6(1), 53-59.

Serin, N. B., Serin, O., Yavuz, M. A., \& Muhammedzade, B. (2009). The Relationship between the Primary Teachers' Teaching Strategies and their Strengths in Multiple Intelligences (Their multiple intelligence types) (Sampling: Izmir and Lefkosa). Procedia - Social and Behavioral Sciences, 1(1), 708-712. https://doi.org/10.1016/j.sbspro.2009.01.124

Sorin-Avram, V. (2014). From Theory to Practice: The Multiple Intelligences Theory Experience in a Romanian Secondary School. Procedia - Social and Behavioral Sciences, 116, 5020-5024. https://doi.org/10.1016/j.sbspro.2014.01.1066

Sumantri, M. S. (2015). Strategi Pembelajaran Teori dan Praktik di Tingkat Pendidikan Dasar. Jakarta: Rajawali Pers. Syah, M. (2011). Psikologi Belajar. Jakarta: Rajawali Press.

Voss, T., Wagner, W., Khusmann, U., Trautwein, U., \& Kunter, M. (2017). Changes in Beginning Teachers' Classroom Management Knowledge and Emotional Exhaustion During the Induction Phase. Contemporary Educational Psychology. https://doi.org/10.1016/j.cedpsych.2017.08.002

Wang, F. H. (2017). An Exploration of Online Behaviour Engagement and Achievement in Flipped Classroom Supported by Learning Management System. Computers \& Education, 12, 112-117. https://doi.org/10.1016/j.compedu.2017.06.012

Yeganeh, M. T., \& Dezfouli, F. B. (2015). The Reflection of Multiple Intelligences (MI) in Iranian English Textbooks, Teachers' Perception. Procedia - Social and Behavioral Sciences, 192, 11-14. https://doi.org/10.1016/j.sbspro.2015.06.002 